SMAD, Rev. Eletrônica Saúde Mental Álcool Drog.

2021 jan.- mar:;17(1):7-16

DOI: 10.11606/issn. 1806-6976.smad.2021.167996

www.revistas.usp.br/smad/

Artigo Original

\title{
Binge drinking e fatores associados em indígenas da etnia Karipuna*
}

\author{
Fernanda Matos Fernandes Castelo-Branco ${ }^{1}$ \\ (D) https://orcid.org/0000-0002-9074-0963 \\ Divane de Vargas ${ }^{2}$ \\ (D) https://orcid.org/0000-0003-3140-8394
}

Objetivo: identificar a prevalência do uso em binge em indígenas Karipuna e verificar a associação desse uso com variáveis sociodemográficas, clínicas e comportamentais da amostra. Método: trata-se de um estudo transversal realizado com 230 indígenas de 12 aldeias Karipuna em Oiapoque. Obteve-se o rastreio do uso em binge por meio da QuestãoChave. Coletaram-se os dados entre maio e dezembro de 2017. Realizaram-se, a priori, a análise de frequência das variáveis envolvidas no estudo e, na sequência, o teste qui-quadrado e o modelo de regressão logística. Resultados: revela-se que a prevalência do uso em binge foi de $24,8 \%$ de uma a três vezes; de $20,4 \%$ de quatro a seis vezes; de $12,2 \%$ de sete a dez vezes e de 9,6\% em mais de dez vezes. Associaramse os seguintes fatores: estudante $(O R=2,99)$; migração da aldeia de origem $(O R=2,22)$; uso de preservativo $(O R=2,62)$ e relações sexuais após o consumo de álcool $(O R=1,61)$. Conclusão: alerta-se que o uso ocasional de risco de álcool demanda consideração, bem como o conhecimento das particularidades da população ora investigada, a fim de estabelecer controle, planejamento de recursos terapêuticos para que se alcancem resultados efetivos nas ações planejadas e principalmente nas que são adotadas na prática a fim de prevenir um uso abusivo de álcool.

Descritores: População Indígena; Transtornos Induzidos por Álcool; Transtornos Relacionados ao Uso de Substâncias; Abuso de Álcool; Binge Drinking.

\section{Como citar este artigo}

Castelo-Branco FMF, Vargas D. Binge drinking and associated factors in indigenous people from Karipuna. SMAD, Rev Eletrônica Saúde Mental Álcool Drog. 2021 jan.- mar.;17(1):7-16. doi: https://dx.doi.org/10.11606/issn.1806-6976.smad.2021.167996 


\section{Binge drinking and associated factors in indigenous people from Karipuna}

Objective: to identify the prevalence of use in binge in indigenous Karipuna and to verify the association of this use with sociodemographic, clinical and behavioral variables of the sample. Method: this is a cross-sectional study carried out with 230 indigenous people from 12 Karipuna villages in Oiapoque. Binge use screening was obtained through the Key Question. Data was collected between May and December 2017. A priori, the frequency analysis of the variables involved in the study was carried out, following the chi-square test and logistic regression model. Results: it is revealed that the prevalence of use in binge was $24.8 \%$ from one to three times; $20.4 \%$ four to six times; $12.2 \%$ seven to ten times and $9.6 \%$ more than ten times. The following factors were associated: student $(O R=2.99)$; migration from the village of origin ( $O R=2.22)$; condom use $(O R=2.62)$ and sexual intercourse after alcohol consumption (OR = 1.61). Conclusion: it is warned that the occasional use of alcohol risk demands consideration, as well as knowledge of the particularities of the population now investigated, in order to establish control, planning of therapeutic resources so that effective results are achieved in the planned actions and especially in those that are adopted in practice in order to prevent alcohol abuse.

Descriptors: Indigenous Population; Alcohol-Induced Disorders; Disorders Related to Substance Use; Alcohol Abuse; Binge Drinking.

\section{Binge drinking y factores asociados en indígenas de la etnia Karipuna}

Objetivo: identificar la prevalencia del uso de binge en indígenas Karipuna y verificar la asociación de este uso con las variables sociodemográficas, clínicas y comportamentales de la muestra. Método: se trata de un estudio transversal realizado con 230 indígenas de 12 aldeas Karipuna en Oiapoque. Se obtuvo el rastreo del uso de binge por medio de la pregunta clave. Se recogieron los datos entre los meses de mayo y diciembre de 2017. Se realizaron, a priori, el análisis de la frecuencia de las variables del estudio y a continuación se realizó el test chi-cuadrado y el modelo de regresión logístico. Resultados: se revela que la prevalencia del uso de binge fue de $24,8 \%$ de una a tres veces; de $20,4 \%$ de cuatro a seis veces; de $12,2 \%$ de siete a diez veces y de $9,6 \%$ en más de diez veces. Se asociaron los siguientes factores: estudiante $(O R=2,99)$; migración de la aldea de origen $(O R=2,22)$; uso de preservativo $(O R=2,62)$ y relaciones sexuales después de consumo de alcohol $(\mathrm{OR}=1,61)$. Conclusión: se advierte que el uso ocasional de riesgo de alcohol demanda atención, así como tomar conocimiento de las particularidades de la población que está siendo investigada, con la finalidad de establecer control y planificar recursos terapéuticos, para que sean alcanzados resultados efectivos, en las acciones planificadas y, principalmente, en aquellas que son adoptadas en la práctica, con la finalidad de prevenir el uso abusivo del alcohol.

Descriptores: Población Indígena; Trastornos Inducidos por el Alcohol; Trastornos Relacionados con el Uso de Sustancias; Abuso de Alcohol; Beber en Exceso. 


\section{Introdução}

O uso do álcool em comunidades indígenas é um fenômeno complexo, pois exige a ponderação e a compreensão dos diferentes saberes do consumo de bebidas alcóolicas entre os grupos que apresentam diferenças culturais.

Especificamente, o álcool é utilizado pelas comunidades em diversas situações, tais como: cerimônias religiosas (casamentos, batizados); comemorações (aniversários, Dia do Índio); em trabalhos comunitários (limpeza das aldeias, reforma de escolas, trabalhos de roças e colheitas) ou no ritual de iniciação masculina (ocorre com os meninos a partir dos 15 anos, os quais são submetidos a testes de masculinidade e resistência). Porém, esse uso tradicional tomou proporções diferenciadas, tornou o consumo muitas vezes abusivo e a oferta de bebidas o principal atrativo para a participação do grupo nas atividades ${ }^{(1-2)}$.

Em se tratando de uso tradicional, destaca-se o caxixi (bebida fermentada em potes de barros especiais, feita a partir de mandioca, milho cozido ou frutas fermentadas e de produção essencialmente feminina) como uma bebida alcoólica amplamente utilizada em comunidades indígenas no Brasil, muitas vezes, associada ao Turé (dança executada de forma coletiva, passada de geração a geração, que constitui uma simbologia de amizade entre os povos da aldeia)(3).

Estudo que objetivou identificar a microbiota presente e caracterizar físico-quimicamente a bebida caxixi produzida pelos índios Juruna no Mato Grosso evidenciou que sua graduação alcoólica é de $10^{\circ}$ a $11^{\circ}$ GL (próxima dos teores alcoólicos fermentados de frutas) e seu processamento é realizado com adição de bebidas destiladas e sucos de frutas, o que a levou à classificação de "outra bebida fermentada"(4). Evidencia-se, assim, um estreitamento do caxixi com as bebidas industrializadas. Dentre as outras bebidas consumidas, há mais de três séculos, a cachaça tem se tornado muito difundida entre estes povos, provavelmente pelo contato interétnico(5).

Apesar de todo um contexto simbólico e em se tratando de culturalidade versus bebidas alcóolicas, estas são subordinadas à socialização e ao valor simbólico que carregam, pois, entre os indígenas, não se definem por quantidade consumida e sim pelo significado e o contexto em que se consomem ${ }^{(6)}$.

Nesse âmbito, e não obstante mudanças ocorridas nesse consumo tradicional, não se pode pensar no uso do álcool focando-se apenas consequências negativas, pois é notório que, apesar dos prejuízos causados, o consumo dessas substâncias ainda se encontra fortemente atrelado a significados históricos e culturais.

Objetivou-se, por este estudo, considerando a necessidade de investigar o consumo ocasional de risco, ou seja, o binge drinking (BD) em comunidade indígenas de Oiapoque, mais especificamente na etnia Karipuna, e levando em conta que esses achados podem contribuir para o desenvolvimento de estratégias de prevenção acerca do uso problemático de álcool, identificar a prevalência do uso em BD em indígenas Karipuna e verificar a associação desse uso com variáveis sociodemográficas, clínicas e comportamentais da amostra.

\section{Método}

Trata-se de um estudo exploratório e transversal. O estudo foi conduzido em 12 aldeias da etnia Karipuna, no município de Oiapoque, no Estado do Amapá.

Doze aldeias (Açaizal, Ahumã, Benoá, Espírito Santo, Estrela, Cariá, Curipi, Manga, Pakapuá, Paxiubal, Santa Isabel e Taminã) autorizaram a realização da pesquisa e constituíram-se como locais desta pesquisa. Em levantamento informal realizado pelos autores do estudo junto aos caciques e lideranças indígenas, indica-se que atualmente estas comunidades somam 2446 habitantes, portanto, uma estimativa superior ao último levantamento em órgão oficial, ou seja, da Fundação Nacional do Índio, que apontou 2210 indígenas.

Foram convidados a participar do estudo todos os indivíduos com idade igual ou superior a 15 anos, que moram nas 12 aldeias envolvidas no estudo, pertencentes ao município de Oiapoque, no Estado do Amapá, em região fronteiriça com a Guiana Francesa, no período compreendido entre maio e dezembro de 2017.

Os critérios de inclusão na amostra foram: pessoas que se autodeclararam indígenas; indígenas que vivem aldeados; idade igual ou superior a 15 anos de ambos os sexos e que compreendiam a língua portuguesa. Foram excluídos da amostra indivíduos que, no momento da coleta, apresentaram alterações de comportamentos visíveis, estavam intoxicados, que não concordaram em participar do estudo, recusando-se a responder aos questionários mediante a leitura e assinatura do Termo de Consentimento Livre e Esclarecido (TCLE), que não residiam na aldeia selecionada ou estivessem impossibilitados permanentemente (deficientes auditivo ou mental).

O cálculo amostral foi estimado com base no estudo, citado na pesquisa(7) que investigou a prevalência de alcoolismo na população Terena no Estado do Mato Grosso do Sul, em população acima de 15 anos, cuja prevalência foi de $17,6 \%$. Para o dimensionamento amostral e alocação proporcional da amostra, foi utilizada a equação de população finita.

De acordo com os cálculos, considerando-se a população que estava de acordo com os critérios de inclusão, o tamanho mínimo da amostra - com base na prevalência presumida de estudo citado acima, com margem de erro de 5\%, um intervalo de confiança de 95 - resultou em 202 indivíduos. Embora o cálculo amostral 
tenha sido de 202 indivíduos, a amostra constitui-se de 230 indivíduos da etnia Karipuna; assim, foi adotado um número superior devido às possíveis perdas que poderiam ocorrer durante a coleta de dados.

Utilizou-se a amostra de seleção aleatória simples na constituição da amostra. Para a coleta de dados, os pesquisadores participaram de assembleias com parte da comunidade, caciques envolvidos e órgãos competentes para a liberação do campo. A equipe foi previamente treinada a fim de garantir maior fidedignidade dos dados, bem como realizou-se um teste piloto a fim de se adaptar à realidade da comunidade indígena envolvida juntamente com alunos da mesma etnia que frequentam o campus universitário de Oiapoque.

Foram aplicados um questionário com características clínicas, sociodemográficas e comportamentais e, para a identificação do uso em BD, a Questão-Chave (QC).

A QC foi direcionada a buscar a quantidade de vezes de álcool ingerido pelos indígenas no último ano. A QC foi proposta, pela primeira vez, no final da década dos anos 90 , em estudo realizado( ${ }^{(8)}$ que tinha por pergunta base: "Have you ever had drinking problem?". Em tradução direta, seria: "Você já teve problemas com beber?", traduzida e validada em estudo(9) que denominou a Single Question como Questão-Chave e explicou que esta apresentou boa concordância entre os juízes em relação ao conteúdo e com desempenho psicométrico.

Trouxe, ainda, em seu estudo, levantamento de diversas pesquisas que foram feitas e modificaram a pergunta para melhor entendimento e compreensão; comentou, ainda, que estudos já foram realizados para testar a sensibilidade, que é de $80 \%$, e a especificidade, de $74 \%$, não apresentando diferença significativa de parâmetro entre sexo e etnias. Acrescentou, também, em seu estudo, que a QC apresentou bom desempenho na versão inglesa e apontou resultados satisfatórios da versão em português, caracterizando-se como um instrumento universal.

É um instrumento prático, de baixo custo e que se adequa a todos os tipos populacionais, portanto, uma boa estratégia para rastreio do uso risco/nocivo em serviços de atenção básica(10).

A análise dos dados foi realizada por meio do software Excel de modo a permitir a checagem de erro na digitação e devidas correções. A análise estatística foi obtida usando-se o software estatístico SPSS, versão 20.0. Inicialmente, foi feita a análise de frequência dos dados sociodemográficos clínico-comportamentais, apresentando-os sob a forma de tabelas. Em um segundo momento, foi feita a análise bivariada/multivariada, com o teste qui-quadrado ( $p$-valor de significância 0,05 ), para verificar a associação entre as variáveis e os padrões do consumo de álcool. Posteriormente, foram selecionadas as variáveis para compor o modelo de regressão logística. A escolha das variáveis para compor o modelo de regressão logística deu-se com a prefixação do p-valor em, no máximo, 0,20. Foram obtidos os valores das Odds Ratio (OR), bem como Intervalo de Confiança (IC) de 95\% para a avaliação da razão de chance entre as variáveis selecionadas na regressão logística.

Esta pesquisa foi realizada respeitando-se a Resolução do Conselho Nacional de Saúde/CNS Número $466 / 2012$, que estabelece as Diretrizes e Normas Reguladoras de Pesquisa envolvendo Seres Humanos(11), e a Resolução 304/00, no que se refere a pesquisas com populações indígenas ${ }^{(12)}$. Portanto, seguiu todos os trâmites burocráticos necessários envolvendo seres humanos e terras indígenas, tendo sido aprovada com o Parecer No 1.872 .185 .

\section{Resultados}

A amostra caracterizou-se predominantemente como do sexo masculino (51,3\%), na faixa etária de 16 a 30 anos (46,5\%), em união estável/amigado $(55,7 \%)$, por católicos $(71,1 \%)$, com Ensino Fundamental incompleto $(28,3 \%)$, trabalhadores ativos $(45,9 \%)$ e sem renda (53,5\%).

Em se tratando dos processos migratórios, 79,9\% dos entrevistados afirmaram que já migraram da aldeia de origem; 76,6\% moraram em outro território indígena na região Norte e 36,2\% relataram mudança para constituição de família.

A amostra evidenciou que $19 \%$ têm alteração de pressão, 3,1\%, diabetes, 5,4\%, depressão, 13,5\% pensaram em suicídio, 9,5\% tentaram suicídio, 9,6\% não informam se têm parceiro fixo, $48,6 \%$ não usam preservativo, $0,5 \%$ já foi diagnosticado com infecção sexualmente transmissível; todos negaram HIV/Aids e $35,6 \%$ afirmaram relações sexuais após consumo de álcool e outras drogas, ressaltando que esses dados foram baseados em autorrelatos.

Na caracterização do consumo de álcool, 70\% afirmaram usar bebidas alcóolicas; a cerveja destaca-se como a bebida mais consumida $(51,6 \%)$; idade de início de uso de nove a 20 anos $(90,1 \%)$; local de primeiro contato com a bebida foram as festas sociais $(27,3 \%)$; $70,8 \%$ afirmaram que os locais de primeiro contato ficavam na própria aldeia; o local de maior consumo de bebidas alcóolicas $(32,3 \%)$ dos entrevistados era a casa, sendo que $90,1 \%$ afirmaram ser na própria aldeia; quando indagados sobre o local onde costumavam comprar/ adquirir bebidas alcóolicas, 59\% citaram os mercados e $62,7 \%$ disseram ser este o local de mais fácil acesso à compra do álcool; $59 \%$ dos investigados afirmaram que a bebida nunca Ihes causou tipo algum de problema; 49,7\% consideraram que os grupos de amizade foram o principal motivo que os levou a beber; $88,3 \%$ afirmaram ter algum membro familiar que consome bebidas alcóolicas e a mãe 
é o membro mais citado ( $41,4 \%)$. Quando questionados se consideram o uso de bebidas alcóolicas um problema na comunidade, $85,7 \%$ afirmaram que sim, sendo o problema mais citado $(70,6 \%)$ as mudanças de comportamento.

Quando utilizada a QC para saber quantas vezes os homens tinham bebido cinco doses ou mais e as mulheres quatro doses ou mais, em uma mesma ocasião, ou seja, o uso em binge, no último ano, foram encontrados os seguintes dados: $33 \%$, nenhuma vez (lembrando-se que, neste percentual, se encontram pessoas abstinentes, bem como pessoas de uso ocasional/baixo risco); $24,8 \%$, de uma a três vezes; $20,4 \%$, de quatro a seis vezes; $12,2 \%$, de sete a dez vezes e 9,6\% mais de dez vezes, ou seja, que fazem uso em binge, ultrapassando o limite de doses seguras e adotando um uso de risco, como se observa na Figura 1.

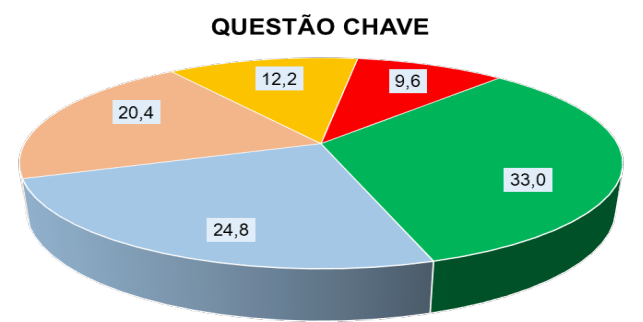

- Nenhuma vez $=$ De 1 a 3 vezes $=$ De 4 a 6 vezes $=$ De 7 a 10 vezes $=$ Mais de 10 vezes

Figura 1 - Uso em binge (Questão-Chave - QC)

A associação entre as variáveis estudadas por meio da análise bivariada não demonstrou significância entre a QC e as variáveis: idade; sexo; estado civil; religião; escolaridade e renda. Portanto, estas não foram incorporadas aos modelos múltiplos de regressão logística.

Já as variáveis ocupação e migração da aldeia de origem são significativamente estatísticas, com $\mathrm{p}$ valor de 0,002 e 0,03, respectivamente, como se pode observar na Tabela 1.

As variáveis alteração de pressão, diabetes, depressão, Infecções Sexualmente Transmissíveis - IST, HIV/Aids, pensar em suicídio, tentar o suicídio e ter parceiro fixo não apresentaram associação estatística significativa com o padrão de uso. Enquanto o uso de preservativo $(p<0,001)$ e manter relações sexuais após consumo de sustâncias psicoativas $(p=0,04)$ deram associação significativa, como se pode observar na Tabela 1.

A Tabela 2 mostrou que ser estudante tem 2,99 mais chances de fazer uso de álcool em binge quando em comparação a ser aposentado. Os indígenas que migraram da aldeia de origem têm 2,22 mais chances de consumo em binge quando comparados aos indivíduos que não migraram. E aquelas pessoas que usam preservativo $(O R=2,62)$ e mantêm relações sexuais após o consumo de álcool e outras drogas $(\mathrm{OR}=1,61)$ apresentam chances aumentadas em fazer o consumo em binge de bebidas alcóolicas.
Tabela 1 - Modelo final da análise bivariada da QC* e as características sociodemográficas, clínicas e comportamentais $(n=230)$. Oiapoque, Amapá, Brasil, 2017

\begin{tabular}{|c|c|c|c|c|c|c|}
\hline \multirow{2}{*}{ Variável } & \multicolumn{2}{|c|}{ Sim } & \multicolumn{2}{|c|}{ Não } & \multirow{2}{*}{ p-valor } & \\
\hline & $\mathbf{N}$ & $\%$ & $\mathbf{N}$ & $\%$ & & \\
\hline \multicolumn{7}{|l|}{ Ocupação } \\
\hline Estudante & 38 & 58,5 & 27 & 41,5 & 0,002 & \\
\hline Ativo & 26 & 29,9 & 64 & 71,1 & & \\
\hline Nenhum & 14 & 45,2 & 17 & 54,8 & & \\
\hline Aposentado & 3 & 30,0 & 7 & 70,0 & & \\
\hline \multicolumn{7}{|l|}{$\begin{array}{l}\text { Migração da aldeia de } \\
\text { origem }\end{array}$} \\
\hline $\operatorname{Sim}$ & 130 & 71,0 & 53 & 29,0 & 0,03 & \\
\hline $\begin{array}{l}\text { Não, mora desde que } \\
\text { nasceu }\end{array}$ & 24 & 52,2 & 22 & 47,8 & & \\
\hline \multicolumn{7}{|l|}{$\begin{array}{l}\text { Uso de } \\
\text { preservativo }\end{array}$} \\
\hline Sim & 84 & & & 25 & 22,9 & $<0,001$ \\
\hline Não & 59 & & & 44 & 42,7 & \\
\hline \multicolumn{7}{|c|}{$\begin{array}{l}\text { Relações sexuais depois de consumir álcool ou } \\
\text { outras drogas }\end{array}$} \\
\hline Sim & 55 & & & 22 & 28,5 & 0,04 \\
\hline Não & 92 & & & 47 & 33,8 & \\
\hline
\end{tabular}

${ }^{*} \mathrm{QC}=$ Questão-Chave

Tabela 2 - Regressão logística, análise da $\mathrm{QC}^{*}$ de acordo com as variáveis significativas no estudo $(n=230)$. Oiapoque, Amapá, Brasil, 2017

\begin{tabular}{|c|c|c|c|c|}
\hline \multirow{2}{*}{ Variáveis } & \multirow[t]{2}{*}{$\mathrm{OR}^{\dagger}$} & \multicolumn{2}{|c|}{ IC $¥(95 \%)$} & \multirow{2}{*}{$\mathbf{P}$} \\
\hline & & Inferior & Superior & \\
\hline \multicolumn{5}{|l|}{ Ocupação } \\
\hline Estudante & 2,99 & 1,51 & 5,96 & 0,02 \\
\hline Ativo & 1,55 & 0,25 & 4,39 & 0,00 \\
\hline Nenhum & 1,70 & 0,72 & 4,02 & 0,22 \\
\hline Aposentado & 1 & - & - & - \\
\hline \multicolumn{5}{|c|}{ Migração da aldeia de origem } \\
\hline Sim & 2,22 & & & \\
\hline $\begin{array}{l}\text { Não, mora desde que } \\
\text { nasceu }\end{array}$ & 1 & - & - & - \\
\hline \multicolumn{5}{|l|}{ Uso de preservativo } \\
\hline Sim & 2,62 & 1,47 & 4,65 & 0,001 \\
\hline Não & 1 & - & - & - \\
\hline \multicolumn{5}{|c|}{$\begin{array}{l}\text { Relações sexuais depois } \\
\text { de consumir álcool ou } \\
\text { outras drogas }\end{array}$} \\
\hline Sim & 1,61 & 0,89 & 2,92 & 0,11 \\
\hline Não & 1 & - & - & - \\
\hline
\end{tabular}

${ }^{*} \mathrm{QC}=$ Questão-Chave $;{ }^{+} \mathrm{OR}=$ Odds Ratio $;{ }^{\ddagger} \mathrm{IC}=$ Intervalo de Confiança

\section{Discussão}

Os dados encontrados na população mostram maior uso de bebidas alcóolicas por homens, entre adolescentes e pessoas no início da idade adulta, que têm companheiro 
(a)/parceiro (a), católicos, com Ensino Fundamental incompleto, trabalhadores ativos e sem renda formal.

Segundo o levantamento realizado sobre os padrões de consumo de álcool e outras drogas em povos indígenas ${ }^{(13)}$, a proporção dos que bebem é maior entre os homens $(52,7 \%)$ do que entre as mulheres $(24,6 \%)$. Em relação à faixa de idade, o mesmo levantamento mostrou que à medida em que a idade aumenta diminui a proporção de usuários. Assim, na faixa de 18 a 34 anos, encontra-se a população que mais consome álcool. Constata-se, ainda, que os usuários preferem consumir álcool na companhia de amigos e que as mulheres preferem beber na companhia do esposo ou companheiro. Os dados deste levantamento corroboram as variáveis sexo, idade e estado civil deste estudo.

Os indivíduos que praticam a religião católica são os mais propensos ao uso de bebidas alcoólicas, algo que pode estar associado à não proibição de consumo de tais substâncias pela doutrina católica. Um fato relevante é a entrada da religião evangélica (protestante) nas aldeias ora investigadas, pois muitos dos indígenas entrevistados afirmaram ter diminuído ou até mesmo interrompido seu consumo de tais substâncias devido à sua nova crença religiosa.

Estudo(1) $^{(1)}$ ostrou que a prática da religião é fator protetivo para a diminuição do consumo exagerado e apontou influência da igreja como medida redutora do consumo de bebidas alcóolicas, pois os praticantes adotaram a postura da "substituição da bebida alcoólica pela aceitação da palavra de Deus" e assumiram comportamentos em que a bebida não faz parte do cotidiano. Os indivíduos que passaram pela conversão religiosa deveriam seguir regras rígidas de conduta e, entre elas, está a proibição ao uso de bebidas alcoólicas ${ }^{(14)}$.

No que concerne a pessoas de baixa escolaridade e sem renda, esta variável está diretamente relacionada à falta de emprego fixo, pois é notória a exigência de qualificação profissional no atual mercado de trabalho, algo que contribui para que muitos indígenas tenham, na agricultura, o eixo de sua subsistência. Ainda nesse sentido, atualmente, é constante a saída de indígenas de suas aldeias em busca de educação e muito disso é devido à chegada da universidade pública na cidade de Oiapoque-AP. A universidade Ihes proporcionou a oportunidade de galgar qualificação técnica em nível universitário, sempre na busca pela melhoria na qualidade de vida e condição socioeconômica. Contudo, o movimento migratório em busca dos estudos universitários acaba por colocar os estudantes indígenas entre o público que mais consome bebidas alcoólicas.

Em se tratando das pessoas que se declararam sem renda, muitas delas são trabalhadoras ativas, ou seja, exercem alguma atividade, mas não necessariamente são remuneradas, pois são agricultoras (es) de subsistência.
Este fato faz refletir sobre outra questão, pois, devido ao ofício exercido, muitos necessitam se deslocar até a cidade para garantir a venda e/ou a troca dos produtos cultivados e produzidos a partir do trabalho da roça, o que facilita o contato com as bebidas alcoólicas e outras drogas, além de adoção dos hábitos da cultura do "homem branco".

A aquisição de bebidas pode ser feita com dinheiro ou como moeda de troca por peixe, farinha e gêneros advindos do plantio. As pessoas que têm trabalho remunerado são as que mais facilmente conseguem a substância; assim, tanto consomem como dividem as bebidas alcóolicas com os demais, gerando-se um grande volume de relações de reciprocidade que norteiam o modo de viver indígena(3).

Todos estes aspectos têm influenciado o modelo de processo migratório, com consequente estreitamento das relações entre os indígenas e não indígenas, quer seja pela facilidade de acesso às aldeias ou mesmo pelos diversos motivos que os indígenas têm para ir até a cidade, algo que é corroborado pelos dados dos processos migratórios encontrados na amostra, que atestam que 79,9\% dos indígenas pesquisados afirmaram ter já saído de sua aldeia originária. Esta informação destoa do estudo(15) no qual a maioria dos indígenas referiu nunca ter saído da terra indígena.

Isto acaba por contribuir para que a inserção e o uso de bebidas alcoólicas sejam facilmente aceitos entre eles, e o álcool torna-se um objeto de fácil consumo e de interação sociocultural, algo que, aos poucos, vem contribuindo para a perda das características culturais desses indígenas.

Nessa vertente, o uso diferenciado das bebidas com teor alcoólico é fruto de mudanças que ocorreram dentro das aldeias, tais como: o contato com o homem branco, denominado contato interétnico; o aumento da circulação de bebidas nas aldeias; mudanças no uso tradicional e de socialização e, por fim, o advento das bebidas industrializadas. $\mathrm{O}$ uso de tais bebidas tem se tornado cada vez mais precoce, além da notória substituição do caxixi pelos destilados, tanto nas situações de consumo coletivo, o que é tido por tradicional, como em sua inclusão nas datas festivas do calendário indígena pela influência da cultura branca(3).

Corrobora-se estudo anterior por pesquisa(16) realizada entre os indígenas da etnia Potiguara, que demonstrou que o uso do álcool está estritamente relacionado à diversão, às festividades e aos rituais indígenas, destacando a cachaça como a bebida mais consumida devido à facilidade de acesso e pelo baixo valor de custo.

No que tange às características clínicas e comportamentais, dentre os entrevistados que consomem bebidas alcóolicas, a maioria negou alteração de pressão, diabetes, depressão, pensamentos e tentativas suicidas, 
infecções sexualmente transmissíveis, HIV/Aids, relações sexuais após consumo de substâncias psicoativas, bem como afirmaram ter parceiro fixo e fazer uso de preservativo por ocasião de relação sexual.

O baixo percentual encontrado dentre estas patologias pode estar associado principalmente ao desconhecimento de tais enfermidades ou simplesmente por terem afirmado não ter tais doenças ou se recusado a responder. Durante a coleta de dados, observou-se que estas comunidades necessitam de mais investigação e reforço de ações preventivas a fim de garantir maior sensibilidade dos instrumentos aplicados quando se pesquisam tais doenças em população indígena e, desse modo, conseguir respostas fidedignas que sustentem o levantamento epidemiológico.

Tudo isso está também associado ao fato de uma parcela significativa das pessoas entrevistadas afirmar que nunca realizou exames específicos em busca de tais diagnósticos, e os resultados são considerados a partir dos dados informados, o que pode não reproduzir a realidade atual dessa população. Isto pode acontecer em face do constrangimento por parte da maioria dos indígenas ao responder questões de cunho íntimo, principalmente no que tange ao ato sexual, algo que interferiu nas respostas e levou a uma subestimação dos dados encontrados.

As doenças transmitidas pelo ato sexual, inclusive a infecção pelo HIV/Aids, são de baixo conhecimento e notificação no Brasil. A insuficiência de informações demonstra que a população indígena se encontra descoberta em relação à saúde e as pesquisas com tal público priorizam as questões étnicas e culturais ${ }^{(17)}$.

Ainda nesse contexto, houve um número significativo de entrevistados que afirmou ter parceiro fixo e fazer uso de preservativos, o que contraria a literatura, que aponta as situações de maior vulnerabilidade relacionadas ao consumo de bebidas alcóolicas nas comunidades indígenas, o não uso de preservativo e aumento de membros da comunidade a frequentar cidades próximas, além de novas relações sociais( ${ }^{(18)}$.

Além das demais doenças clínicas e medidas comportamentais que foram prontamente negadas pela maioria dos entrevistados, existe aumento de distúrbios relacionados ao uso de bebidas alcóolicas entre os indígenas, tais como acidentes, brigas, quedas, atropelamentos e doenças clínicas - cirrose, diabetes, hipertensão arterial, depressão, estresse, dentre outras. Em se tratando de fatores externos, citam-se casos de homicídios, suicídios, violência sexual, incestos etc. ${ }^{(19)}$.

Portanto, o consumo abusivo de álcool é uma realidade que traz inúmeras consequências danosas para a população indígena(20), fato que confirma a necessidade de uma investigação profunda de tais mazelas nesta população.

As taxas de ideias e tentativas suicidas mostraram-se consideráveis, bem como os percentuais de depressão.
O estudo mostrou uma faixa de $13,5 \%$ de pessoas que pensaram em suicídio, 9,5\% já tentaram suicídio e 5,4\% afirmaram depressão, evidenciando-se a necessidade de maior atenção a este fenômeno, pois estudo(21) que buscou fazer um apanhado geral das taxas de suicídio entre os indígenas no Brasil verificou que este ato é bem prevalente em diversas populações. Os autores mostraram que, entre os Ticuna, se atinge uma taxa de $28 \%$; entre os Caiowás, taxa 40 vezes maior que a da média da população brasileira e, entre os Sorowahá, são estimados 1922 casos de suicídio para cada 100 mil habitantes.

Apesar de, nesse sentido, os dados deste estudo mostrarem-se abaixo da média encontrada na literatura, verifica-se um percentual que necessita de melhor investigação e observação por parte dos profissionais de saúde e lideranças indígenas a fim de evitar maiores estragos no futuro, pois pesquisa(22) mostrou que os sintomas depressivos têm estreita relação com os problemas psicossociais entre os povos indígenas e que a avaliação é de suma importância para evitar possíveis danos.

Ao considerara os resultados da QC, que avalia o uso de risco em ocasiões isoladas, ou seja, a mais adequada à realidade da população indígena, mais da metade de homens e mulheres (67\%) tinha consumo superior ao número de "doses seguras" - cinco para homens e quatro para mulheres em uma única ocasião -, evidenciando-se que $42,2 \%$ dos entrevistados fizeram uso de risco (beber em binge) mais de quatro vezes ao ano, e os preditores para esse padrão de uso foram ser estudantes $(O R=2,99)$, ter migrado da aldeia de origem $(O R=2,22)$, uso de preservativo $(O R=2,62)$ e RSACA $(O R=1,61)$.

$\mathrm{O} B \mathrm{D}$, ou beber pesado episódico, é um padrão de consumo de risco que tem despertado interesse internacional e que apenas recentemente começou a ser investigado no Brasil, ainda pouco estudado entre a população brasileira(23).

No ano de 2010, pesquisa feita com estudantes do Ensino Médio das 27 capitais do país revelou uma prevalência de $32 \%$ de prática de uso em binge, maior em adolescentes de melhor poder aquisitivo e nas regiões Norte e Nordeste do Brasil(24). O primeiro levantamento nacional dos padrões de uso de álcool no Brasil, realizado em 2005-2006, identificou uma prevalência de BD no ano anterior à pesquisa de $28 \%$ em adultos ${ }^{(25)}$. Em outra pesquisa, que investigou homens adultos em situação de rua, revelou-se que $46,94 \%$ fizeram uso em binge ${ }^{(26)}$.

Ainda que seja a primeira vez de um estudo que aplica a QC em populações indígenas, ficaram evidentes que os percentuais dos resultados encontrados nesta população são maiores do que os que foram aplicados na população em geral.

Pela ausência de instrumentos adaptados à cultura indígena, foram utilizados instrumentos pautados no modelo biomédico aplicado à população geral, mas foram 
levados em consideração os aspectos socioculturais de uso a fim de garantir maior veracidade nos resultados.

A falta de instrumento de rastreio adequado a essas populações tradicionais - como pode ser claramente evidenciado em estudo(27), que utilizou o Cut down, Annoyed, Guilty, Eyer-opener (CAGE) como instrumento de rastreio - leva à conclusão de que este é inadequado, pois se trata de um procedimento universal utilizado para identificar dependência e é preciso entender as situações sociais, pois essas condições são necessárias para adequar as respostas dos entrevistados. Na população do Alto Rio Negro, consideram-se "beber problema" as pessoas que apresentam comportamento violento, as que são maus exemplos para os filhos e para a comunidade, aquelas que se esquecem de seus atos após ingestão de substâncias alcóolicas, bem como as que apresentam comprometimento das atividades laborais.

Assim, a mensuração em álcool e outras drogas é relevante e mostra a necessidade de maior variedade de instrumentos confiáveis para uso na prática assistencial e no campo da pesquisa, pois estes facilitam a detecção dos comportamentos de risco, uso abusivo, dentre outros aspectos, além de nortearem estratégias de prevenção e planejamento de tratamento e intervenção. Entretanto, é necessário adotar referenciais de adaptação cultural padronizados, que considerem o contexto biopsicossocial do uso problemático(28).

Em relação às limitações deste estudo, podem-se elencar as poucas recusas na amostra selecionada e, quando se explicava a temática do estudo e por serem questionamentos de foro íntimo, utilizou-se uma abordagem cautelosa e esclarecedora, mas, mesmo assim, houve rejeição por parte de alguns indígenas. Logo, na sequência, era selecionado outro participante daquele núcleo familiar que tivesse sido sorteado. Houve ainda o viés de memória, quando se questionava sobre o consumo de álcool no último ano, e aí pode ter havido perda de respostas fidedignas por parte de alguns entrevistados.

As implicações deste estudo para a prática assistencial ocorrem no sentido de contribuir para que órgãos e entidades que tratam da tutela indigenista, governamentais ou não, possam elaborar estratégias e políticas voltadas para o aprimoramento da saúde dessa população vulnerável, especificamente no que se refere ao uso de substâncias psicoativas, algo que proporcionará melhoria na qualidade de vida indígena e otimização do convívio coletivo nas aldeias investigadas por este trabalho.

\section{Conclusão}

Diante de toda essa conjuntura, os aspectos sociodemográficos, clínicos e comportamentais e o uso ocasional de risco de álcool demandam consideração, bem como o conhecimento das particularidades da população ora investigada, a fim de estabelecer controle, planejamento de recursos terapêuticos, para que se alcancem resultados efetivos nas ações planejadas e principalmente nas que são adotadas na prática, a fim de prevenir um uso abusivo de álcool.

A partir dos dados encontrados, sobreleva-se a importância de aprimorar a área de adições dentro das comunidades indígenas, pois se trata de uma temática pouca explorada e que necessita de dados epidemiológicos para nortear ações e medidas futuras pautadas no contexto sociocultural vivenciado dentro de cada etnia indígena, tudo com vistas à prevenção ou mesmo à minimização dos danos causados pelo uso de álcool e outras drogas.

Os dados da amostra pesquisada são relevantes para a visibilidade da temática diante da escassez de estudos na área, bem como para incentivar e contribuir com o desenvolvimento de outras pesquisas junto aos indígenas Karipuna, o que proporcionaria o avanço de trabalhos científicos com as mais variadas etnias indígenas existentes, sendo esta a maior potencialidade deste estudo.

\section{Agradecimentos}

À equipe de pesquisa, caciques e lideranças indígenas e Fundação Nacional do Índio- Oiapoque.

\section{Referências}

1. Ghiggi Júnior A, Langdon EJ. Reflections on intervention strategies with respect to the process of alcoholization and self-care practices among Kaingang indigenous people in Santa Catarina State, Brazil. Cad Saude Publica. 2014 Jun;30(6):1250-8. doi: 10.1590/0102-311x00108613

2. Oliveira M. Alcoolismo entre os Kaingáng: do sagrado e lúdico à dependência. In: Anais do Seminário sobre Alcoolismo e Vulnerabilidade às DST/Aids entre os Povos Indígenas da Macrorregião Sul, Sudeste e Mata Grosso do Sul; 2001. Brasília. Brasília: Ministério da Saúde; 2001. p. 127-48. [cited 2018 Aug 5]. Available from: http://bvsms. saude.gov.br/bvs/publicacoes/021anais_seminario.pdf 3. Souza MLP, Garnelo L. Quando, como e o que se bebe: o processo de alcoolização entre populações indígenas do alto Rio Negro, Brasil. Cad. Saude Publica. 2007 July;23(7):1640-48. doi: 10.1590/ S0102-311X2007000700015

4. Santos CCAA. Identificação da microbiota e caracterização físico-química da bebida fermentada caxiri produzida pelo povo Juruna (Yudjá), Mato Grosso, Brasil [dissertação]. Lavras: Microbiologia Agrícola, Universidade Federal de Lavras; 2010. [cited 2018 Aug 5]. Available from: http://repositorio.ufla.br/jspui/handle/1/4765

5. Souza MLP, Deslandes SF, Garnelo L. Modos de vida e modos de beber de jovens indígenas em um contexto de 
transformações. Cienc Saude Colet. 2010;15(3):709-16. doi: 10.1590/S1413-81232010000300013

6. Dias LF. Uso e abusos de bebidas alcóolicas segundo os povos indígenas do Uaçá. In: Labate BC, Goulart SL, Fiore M, MacRae M, Carneiro H, organizadores. Drogas e cultura: novas perspectivas. Salvador: EDUFBA; 2008. p. 199-217. [cited 2018 Nov 15]. Available from: https:// repositorio.ufba.br/ri/bitstream/ufba/192/1/Drogas\%20 e\%20Cultura.pdf

7. Souza JA, Aguiar JI. O alcoolismo em população Terena no Estado do Mato Grosso do Sul: impacto da sociedade envolvente. In: Anais do Seminário sobre Alcoolismo e Vulnerabilidade às DST/Aids entre os Povos Indígenas da Macrorregião Sul, Sudeste e Mata Grosso do Sul; 2001. Brasília. Brasília: Ministério da Saúde; 2001. p. 149-68. [cited 2018 Aug 5]. Available from: http://bvsms.saude. gov.br/bvs/publicacoes/021anais_seminario.pdfp.

8. Fleming MF, Barry KL, Manwell LB, Johnson K, London R. Brief physician advice for problem alcohol drinkers: a randomized controlled trial in community-based primary care practices. JAMA [Internet]. 1997 Apr [cited 2018 Aug 5]; 277(13):1039-45. Available from: https://www. ncbi.nlm.nih.gov/pubmed/9091691

9. Maciel MED, Vargas D. Cultural adaptation and content validation of the Single-Question for screening alcohol abuse. Rev Esc Enferm USP. 2017:e03292. doi: 10.1590/ S1980-220X2016048703292

10. Mitchell AJ, Brid V, Rizzo M, Hussain S, Meader N. Accuracy of one or two simple questions to identify alcohol-use disorder in primary care: a meta-analysis. Br J Gen Pract. 2014;64(624):408-8. doi: 10.3399/ bjgp14X680497

11. Brasil. Ministério da Saúde. Conselho Nacional de Saúde. Resolução n466, de 12 de dezembro de 2012. Aprova as diretrizes e normas regulamentadoras de pesquisas envolvendo seres humanos. Brasília: MS; 2012. [cited 2018 Aug 5]. Available from: https://conselho. saude.gov.br/resolucoes/2012/Reso466.pdf

12. Brasil. Ministério da Saúde. Conselho Nacional de Saúde. Resolução n. ${ }^{\circ}$ 304/00 de 9 de agosto de 2000. Aprova as Normas para Pesquisas Envolvendo Seres Humanos - Área de Povos Indígenas. Brasília: MS; 2000. [cited 2018 Aug 5]. Available from: https:// unip.br/presencial/pesquisa/comite/pesquisa_seres_ humanos/r_304_00_090800.aspx

13. Brasil. Presidência da República. Secretaria Nacional de Políticas sobre Drogas. Relatório brasileiro sobre drogas. Brasília: SENAD; 2009. [cited 2018 Aug 5]. Available from: https://www.justica.gov.br/central-de-conteudo/ politicas-sobre-drogas/relatorios-politicas-sobre-drogas/ relatoriobrasileirosobredrogas-2010.pdf

14. Coimbra Júnior CEA, Santos RV, Escobar AL, organizadores. Epidemiologia e saúde dos indígenas no Brasil. Rio de Janeiro: Fiocruz; 2003. [cited 2018 Aug
5]. Available from: http://books.scielo.org/id/bsmtd/pdf/ coimbra-9788575412619.pdf

15. Medeiros ACLV. O consumo de bebida alcoólica e o trabalho no povo indígena Xukuru do Ororubá [dissertação]. Recife: Centro de Pesquisa Aggeu Magalhães, Fundação Oswaldo Cruz; 2011. [cited 2018 Aug 5]. Available from: https://www.arca.fiocruz.br/ handle/icict/13298

16. Oliveira RCC, Silva AO, Maciel SC, Melo JRF. Situação de vida, saúde e doença da população indígena Potiguara. Rev Min Enferm [Internet]. 2012 Jan-Mar; [cited 2018 Aug 5]. 16(1):81-90. Available from: http://www.reme. org.br/exportar-pdf/504/v16n1a12.pdf

17. Carvalho NS, Cho R, Flores LP. DST em populações indígenas no Brasil - análise crítica e revisão de literatura. J Bras Doenç Sex Trans. 2011;23(3):142-5. doi: 10.5533/2177-8264-201123307

18. Santos VL, Díaz Bermúdez XP, Toledo LM, Cruz MM, Moreira E. Reflexões sobre as políticas de controle das DST e Aids na população indígena. Rev Tempus [Internet]. 2010 [cited 2018 Aug 5];4(2):89-100. Available from: https://repositorio.unb.br/bitstream/10482/23024/1/ ARTIGO_ReflexoesPoliticas.pdf

19. Souza JA, Oliveira M, Kohatsu M. O uso de bebidas alcóolicas nas sociedades indígenas: algumas reflexões sobre os Kaingáng da bacia do rio Tibagi, Paraná. Coimbra Júnior CEA, Santos RV, Escobar AL, organizadores. Epidemiologia e saúde dos indígenas no Brasil. Rio de Janeiro: Fiocruz; 2003. p. 149-68. [cited 2018 Aug 5]. Available from: http://books.scielo.org/id/bsmtd/pdf/ coimbra-9788575412619.pdf

20. Melo JRFD, Maciel SC, Oliveira RCC, Silva AO. Implicações do uso do álcool na comunidade indígena Potiguara. Physis. 2011;21(1):319-33. doi: 10.1590/ S0103-73312011000100019

21. Oliveira CS, Lotufo Neto F. Suicídio entre povos indígenas: um panorama estatístico brasileiro. Rev Psiquiatr Clín [Internet]. 2003 [cited 2018 Oct 24];30(1):4-10. Available from: http://www.scielo.br/ pdf/rpc/v30n1/20583.pdf

22. Armenta BE, Sittner Hartshorn KJ, Whitbeck LB, Crawford DM, Hoyt DR. A longitudinal examination of the measurement properties and predictive utility of the Center for Epidemiologic Studies Depression Scale among North American Indigenous adolescents. Psychol Assess. 2014;26(4):1347-55. doi: 10.1037/a0037608

23. Sanchez ZM. A prática de binge drinking entre jovens e o papel das promoções de bebidas alcoólicas: uma questão de saúde pública. Epidemiol Serv Saude. 2017;26(1):1958. doi: $10.5123 /$ S1679-49742017000100020

24. Sanchez ZM, Locatelli DP, Noto AR, Martins SS. Binge drinking among Brazilian students: a gradient of association with socioeconomic status in five geo-economic 
regions. Drug Alcohol Depend. 2013;127(1-3):87-93. doi: 10.1016/j.drugalcdep.2012.06.018

25. Laranjeira R, Pinsky I, Sanches M, Zaleski M, Caetano R. Padrão de uso de álcool em brasileiros adultos. Rev Bras Psiquiatr. 2010;32(3):231-41. doi: 10.1590/ S1516-44462009005000012

26. Botti NCL, Castro NCL, Silva AK, Silva MF, Oliveira LC, Castro ACHOA, et al. Padrão de uso de álcool entre homens adultos em situação de rua de Belo Horizonte. SMAD, Rev Eletr Saúde Mental Álcool Drogas [Internet]. 2010 [cited 2018 Aug 5];6(n. esp.):536-55. Available from: http://pepsic.bvsalud.org/pdf/smad/v6nspe/10.pdf 27. Souza MLP, Schweickart JC, Garnelo L. O processo de alcoolização em populações indígenas do Alto Rio Negro e as limitações do CAGE como instrumento de screening para dependência ao álcool. Rev Psiquiatr. Clín. 2007;34(2):906. doi: 10.1590/S0101-60832007000200005

28. Claro HG, Oliveira MAF, Almeida MM, Vargas D, Plaglione HB. Adaptação cultural de instrumentos de coleta de dados para mensuração em álcool e drogas. SMAD, Rev Elet Saúde Mental Álcool Drog [Internet]. 2011 [cited 2018 Aug 5];7(2):71-7. Available from: http://pepsic. bvsalud.org/pdf/smad/v7n2/04.pdf

\section{Contribuição dos Autores}

Concepção e planejamento do estudo: Fernanda Matos Fernandes Castelo Branco e Divane de Vargas. Obtenção dos dados: Fernanda Matos Fernandes Castelo Branco. Análise e interpretação dos dados: Fernanda Matos Fernandes Castelo Branco e Divane de Vargas. Análise estatística: Fernanda Matos Fernandes Castelo Branco e Divane de Vargas. Redação do manuscrito: Fernanda Matos Fernandes Castelo Branco. Revisão crítica do manuscrito: Fernanda Matos Fernandes Castelo Branco e Divane de Vargas.

Todos os autores aprovaram a versão final do texto. Conflito de interesse: os autores declararam que não há conflito de interesse.
Recebido: 21.03.2020

Aceito: 27.05 .2020
Autor correspondente:

Fernanda Matos Fernandes Castelo Branco

E-mail: fmfernandescb@gmail.com

(iD) https://orcid.org/0000-0002-9074-0963
Copyright $\odot 2021$ SMAD, Rev. Eletrônica Saúde Mental Álcool Drog. Este é um artigo de acesso aberto distribuído sob os termos da Licença Creative Commons CC BY-NC.

Esta licença permite que outros remixem, adaptem e criem a partir do seu trabalho para fins não comerciais, e embora os novos trabalhos tenham de lhe atribuir o devido crédito e não possam ser usados para fins comerciais, os usuários não têm de licenciar esses trabalhos derivados sob os mesmos termos. 